Visibility of $D_{3}$ as a Dark Line in the Solar Spectrum.-At a recent meeting of the Royal Astronomical Society, Prof. A. Fowler stated, in a paper on the spectrum of the great sun-spot of February last, that he had, on February 2, observed the helium line $\mathrm{D}_{3}$ as a dark and distorted line in the spectrum of the sun in the region about the spot disturbance. This observation was regarded as unusual, but according to a letter written by Mr. A. Buss to the Observatory (No. 358) it is not at all an uncommon phenomenon, and can be seen frequently if the solar spectrum be closely watched. In fact, Mr. Buss states that, according to his observations with a curved slit spectroscope, $D_{3}$ may be seen as a dark line in every really agitated solar disturbance.

West Hendon House Observatory.-No. 3 of the Publications of the West Hendon House Observatory (Sunderland) is devoted to the observations of variable stars made by Mr. Backhouse during the years I866-1904. The observations of each of the forty-nine stars discussed are set out in detail in tables showing the times of observation, the comparison stars, and the magnitudes according to other catalogues. For a number of stars the observed magnitudes are plotted on a series of curves placed at the end of the volume, with a diagram showing the various gradations of colour employed in the descriptions.

\section{NATURE AND MAN.}

THE annual Romanes lecture was delivered by Prof. E. Ray Lankester, F.R.S., in the Sheldonian Theatre, Oxford, on June 14, on the subject of "Nature and Man." The complete lecture has been published by the Clarendon Press (London: Henry Frowde), and the following abstract indicates a few of the points considered in it.

Prof. Lankester remarked that the subject of his discourse is one which has largely occupied the attention of biologists during the five-and-forty years in which he has followed the results of scientific discovery. Much misconception prevails as to the signification attached to the word " Nature," but the lecturer used it as indicating the entire cosmos of which this cooling globe with all upon it is a portion. Until the eighteenth century the study of nature-nature-knowledge and nature-control-was the appropriate occupation of the learned men at Oxford, and the present peculiar classical edacation is a modern innovation.

During the latter half of the nineteenth century, the observations of nature-searchers made it possible to establish the general doctrine of the evolution of the cosmos, with more special detail in regard to the history of the earth and the development of man from a lower animal ancestry. The general process by which the higher and more elaborate forms of life, and eventually man himself, have been produced was shown by Darwin to depend upon heredity and variation. By the process of natural selection, those organisms survive which are most fitted to the special conditions under which they live. Man eventually emerged from the terrestrial animal population strictly controlled and moulded by natural selection. The leading feature in the development and separation of man. from other animals is the relatively large size of his brain, which has five or six times the bulk (in proportion to his size and weight) of that of any other surviving Simian. The development of the mental qualities has given rise to attributes which are peculiar to man, and justify the view that man forms a new departure in the gradual unfolding of nature's predestined scheme.

"Civilised man has proceeded so far in his interference with extra-human nature, has produced for himself and the living organisms associated with him such a special state of things by his rebellion against natural selection and his defiance of nature's pre-human dispositions, that he must either go on and acquire firmer control of the conditions or perish miserably by the vengeance certain to fall on the half-hearted meddler in great affairs." It is practically certain that all epidemic disease could be abolished. within a period so short as fifty years if the State cared to take the matter in hand and employ the means at the command NO. I860, voL. 72 ] of science. If more men were encouraged to study and experiment on this matter, there would soon be an end of all infectious disease.

By the exercise of his will, man has done much to control the order of nature, and it is urgent for him to apply his whole strength and capacity in gaining further control. Little, however, is being done in this direction, but when a knowledge of the situation reaches the masses of the people, "the democracy will demand that those who expend the resources of the community, and as Government officials undertake the organisation of the defence and other great public services for the common good, shall put into practice the power of nature-control which has been gained by mankind, and shall exert every sinew to obtain more. To effect this, the democracy will demand that those who carry on public affairs shall not be persons solely acquainted with the elegant fancies and stories of past ages, but shall be trained in the acquisition of natural knowledge and keenly active in the skilful application of nature-control to the development of the well-being of the community,"

The concluding subject of the lecture was the influence exerted by the University of Oxford upon the welfare of the State and of the human community in general. Oxford by its present action in regard to the choice of subjects of study "is exercising an injurious influence upon the education of the country, and especially upon the education of those who will hereafter occupy positions of influence, and will largely determine both the action of the State and the education and opinions of those who will in turn succeed them." Is it desirable to continue to make the study of two dead languages the main, if not the exclusive, matter to which the minds of the youth of the well-to-do class are directed by our schools and universities? In view of modern needs it would be more sensible to make the chief subject of education for everybody " a knowledge of nature as set forth in the sciences, which are spoken of as physics, chemistry, geology, and biology." The ablest youths of the country should be encouraged to proceed to the extreme limit of present knowledge of one of these branches of science so that they might become makers of new knowledge, and the possible discoverers of enduring improvements in our control of nature. The great prizes of life ought to be given to the young man who pursues natureknowledge successfully rather than to him who takes up less important subjects. In other words, it is desirable that our scheme of education should centre round a knowledge of nature and not continue to be mainly classical and historical.

Though men of science would make natural knowledge the core of education, they would consider it incomplete if a serviceable knowledge of foreign languages, and a real acquaintance with the beauties of English and other literature, were not added. "The studies of the past carried on at Oxford have been charming and full of beauty, whilst England has lain, and lies, in mortal peril for lack of knowledge of nature."

The suggestion "that Oxford should resign herself to the overwhelming predominance given to the study of ancient elegance and historic wisdom within her walls" is an insult to her and an impossibility. Only a few decades have passed since Oxford sent out Robert Boyle and Christopher Wren. Moreover, Oxford exerts an immense influence on the schools, and for this reason men of science cannot be content with the maintenance by the university of the compulsory study of Greek and Latin, and the neglect to make the study of nature an integral and predominant part of every man's education. For " the knowledge and control of nature is man's destiny and his greatest need."

\section{SCIENCE AND THE STATE.}

THE seventh of the series of weekly pamphlets which 1 are appearing under the editorship of Mr. W. T. Stead, with the general title of "Coming Men on Coming Questions," is by Mr. R. B. Haldane, and is entitled "The Executive Brain of the British Empire." Mr. Haldane is an enthusiast for higher education. He is a thorough believer in the policy which has been advocated 